\title{
Alcoholic Extract of Wrightia tinctoria leaves and Isolates there of afford DNA Protection in Post Irradiated Sprague Dawley Rats
}

\author{
Sathianarayanan "', Asha Jose², Ranganathan Balasubramanian', Diana Thomas, Ashitha Balakrishnan', Rajasekaran Aiyalu³ \\ 'Department of Pharmaceutical Chemistry, Amrita School of Pharmacy, Amrita Vishwa Vidyapeetham University, AIMS Health Sciences Campus, Ponekkara PO, \\ Kochi-682041, Kerala, INDIA. \\ 2Department of Pharmacology, JSS College of Pharmacy, JSS University, Udhagamandalam-643001, Tamilnadu, INDIA. \\ ${ }^{3}$ Department of Pharmaceutical Chemistry, KMCH College of Pharmacy, Kovai Estate, Kalapatti Road, Coimbatore-641048, Tamilnadu, INDIA. \\ ${ }^{4}$ College of Medicine and Dentistry, James Cook University, Townsville, AUSTRALIA.
}

\begin{abstract}
Objective: The current study investigates the potential of alcoholic extract of Wrightia tinctoria leaves and its isolates in repairing the DNA damage induced by gamma radiation. Methodology: The ethanolic extract of Wrightia tinctoria (EEWT) the leaves was subjected to in vitro anti oxidant assay by DPPH radical scavenging and hydrogen peroxide scavenging methods. He EEWT was investigated to the Micronucleus assay, spleen colony assay and comet assay in Sprague Dawley rats wherein DNA damage had already been induced by irradiation. Results: The ethanolic extract of Wrightia tinctoria leaves having good antioxidant activity. In the micronucleus assay, a 2 Gy quantum of whole-body gamma radiation significantly enhanced the levels of micronucleated reticulocytes and this induction was substantially reversed in the extract treatment group. Results of the spleen colony assay pointed to the extract's ability to enhance the recovery of the hematopoietic system, in a dose-dependent manner, following 6 Gy gamma irradiation. The decrease in cellular repair index due to enhanced DNA repair was evident from the comet assay parameters. Moreover, the isolates from ethanolic extract of Wrightia tinctoria, when imperiled to DNA
\end{abstract}

protection by in vitro gamma radiation method in plasmid pBR322 DNA abetted DNA repair at higher dose. Conclusion: The DNA protection afforded is likely attributable to free radical scavenging properties along with a potential for regenerating the immune system through repair of post irradiated DNA.

Key words: Comet assay, DNA damage, Micronucleus assay, Radioprotective, Spleen colony assay, Wrightia tinctoria.

Correspondence :

Dr. Sathianarayanan

Department of Pharmaceutical Chemistry, Amrita School of Pharmacy, Amrita Vishwa Vidyapeetham University, AIMS Health Sciences Campus, Ponekkara PO, Kochi-682041, Kerala, INDIA.

Tel no: +91-9496042083; Fax no: +91-0484-2802020

E-mail: ssnvij@yahoo.co.in

DOI: 10.5530/jyp.2016.4.16

\section{INTRODUCTION}

The cellular damage by ionizing radiation is effected primarily via the intermediacy of reactive oxygen species (ROS) which cause lesions in deoxyribonucleic acid (DNA) leading to cell death and mutations. ${ }^{1}$ Apart from producing hydrogen peroxide $\left(\mathrm{H}_{2} \mathrm{O}_{2}\right)$ and molecular hydrogen $\left(\mathrm{H}_{2}\right)$, water radiolysis generates a group of highly reactive odd electron species such as hydrogen $(\mathrm{H} \cdot)$, hydroxyl $(\mathrm{OH} \cdot)$, hydroperoxyl (HOO.) radicals as well as superoxide anion $\left(\mathrm{O}_{2}{ }^{-}\right)$, which are all responsible for causing radiation injury to living cells. ${ }^{2}$ Chemical alterations in DNA, including (a) sugar oxidation, (b) disruption in base-sugar and/or sugarphosphate backbone, in turn leading to strand breaks of the single as well as double strand varieties and (c) release of terminal phosphates represent the major fates of reactions of these free radicals. While single strand breaks undergo repair relatively easily, those involving both the DNA strands cause more serious consequences.

When double strand breaks are introduced within mammalian chromosomes, improper DNA repair produces gross chromosomal rearrangements, ultimately resulting in chromosomal aberrations and the formation of micronuclei. Unrepaired strand breaks of this type are considered to be the primary lesions associated with cell death and have been intimately linked to the cytotoxic effects of ionizing radiation. ${ }^{3}$ It is fairly well established that mutagenesis and carcinogenesis are the consequences of replication occurring in damaged genomic DNA. ${ }^{4}$ Highly coordinated and integrated DNA damage checkpoints as well as repair pathways comprise the typical means through which living cells respond to such a challenge; however, failures do occur during these corrective processes leading to mutations or cancer.

Given that mitochondria is the major site of ROS production, there has been a greater emphasis in recent years towards understanding the impact of oxidants on this organelle and on the proteomic system thereof. Cellular proteins seem to be the major biochemical entities that are initially attacked by hydroxyl radicals generated during radiation. ${ }^{5}$ Most living cells experience a constant burden of oxidative stress leading to deleterious oxidative bio transformations in their cellular proteins, negatively impacting their homeostasis and maintenance. ${ }^{6}$

The development of novel and safe approaches to counter radiation damage using effective radioprotectors has garnered considerable pharmaceutical interest. Apart from protecting healthy tissues during radiotherapy of tumors and related medical diagnostic exposures, these agents would help deal with radiation leakage situations such as those encountered in defense missions, nuclear industries and space travel. ${ }^{7}$ Among the different entities known to exhibit radioprotective effects, ${ }^{8}$ amifostine is a clinically accepted small molecule but suffers from severe adverse effects. Potential new plant-derived candidate drugs for mitigating radiation injury have slowly emerged because of a detailed and systematic screening approach.

The medicinal plant Wrightia tinctoria (commonly known as 'jaundice cure tree' and here in after represented as $W$. tinctoria) belonging to the family apocynaceae possesses good antioxidant effect and radioprotective effect. Many parts of this tree, native to India and Burma, have been extensively used for addressing psoriasis and jaundice in the Indian system of medicine. ${ }^{9}$ While the whole plant displayed antinociceptive activity ${ }^{10}$ and was effective against psoriasis and non-specific dermatitis, ${ }^{11}$ the seeds find use as astringent, carminative, depurative and febrifuge. ${ }^{12}$ The leaves of $W$. tinctoria have immunomodulatory, ${ }^{13}$ anti-inflammatory and diuretic activities ${ }^{14}$ apart from eliciting good effect against hepatitis $\mathrm{C}$ virus. ${ }^{15}$ In addition, the plant is a constituent of many common hair oil preparations on account of its good anti-dandruff properties. ${ }^{16}$ Yielding a 
blue dye called Pala indigo, ${ }^{17}$ its pungent fresh leaves may be munched to quickly relieve toothaches. The present work was focused on examining the radioprotective effects of the alcoholic extract of $W$. tinctoria leaves against mitochondria and its proteomic system.

\section{MATERIALS AND METHODS}

Animals: Sprague Dawley (SD) rats that were obtained from the Small Animal Breeding Section (SABS), Kerala Agricultural University (Kerala, India) were in the age group of 8 to 10 weeks and weighed anywhere from 120 to $150 \mathrm{~g}$. Besides being housed under standard conditions of temperature and humidity, these animals were provided with standard mouse chow (Sai Durga Feeds and Foods, Bangalore, India) and water ad libitum. All animal experiments that formed a part of this investigation were carried out with the prior approval of the Institutional Animal Ethics Committee (IAEC). Moreover, they were performed in strict accordance to the guidelines of Committee for the purpose of Control and Supervision of Experiments on Animals (CPCSEA), a body constituted by the Animal Welfare Division - Government of India.

Plant materials: W. tinctoria samples were collected from Watrap area, Virudhunagar district, Tamilnadu, India. The collected plant material was taxonomically identified.

Chemicals: Ethylenediaminetetraacetic acid (EDTA), 2,2-diphenyl1-picrylhydrazyl (DPPH), silver nitrate, ammonium nitrate, zinc sulphate heptahydrate and tungstosilicic acid were obtained from Merck Specialties Pvt. Ltd. (Mumbai, India). Silica gel 100-200 mesh (Qualigens Fine Chemicals, Mumbai, India), sephadex LH-20 (Fluka, Buchs, Switzerland), precoated silica gel G F-254 thin layer chromatography (TLC) plates $(20 \times 20 \mathrm{~cm}, 0.5 \mathrm{~mm}$ thick), chloroform, methanol, ethyl acetate, dichloromethane, hexane, dimethyl sulfoxide (DMSO) and potassium bromide were procured from E. Merck Ltd. (Mumbai, India). Whereas acridine orange, high melting point agarose and low melting point agarose were from Sigma Chemical Company Inc. (St. Louis Missouri USA), the tetramethylsilane (TMS) used was a Sigma-Aldrich product. All other chemicals were of analytical grade and procured from Nice Chemicals Pvt. Ltd. (Kochi, India).

Instruments: Dried Borosil glassware was used where necessary. Melting points were determined using capillary tubes on Veego-VMP apparatus. Infrared (IR) spectra were recorded on a Shimadzu Affinity-1 FT-IR spectrophotometer using potassium bromide pellet technique. ${ }^{1} \mathrm{H}$ and ${ }^{13} \mathrm{C}$ NMR spectra were recorded using Bruker Spectrospin $400 \mathrm{MHz}$ spectrometer with TMS as internal standard. Deuterated DMSO and methanol were used as the solvents for recording the NMR spectra and the chemical shifts were expressed as delta $(\delta)$ values relative to TMS in units of ppm. Mass spectra of the samples were recorded on MSMS-QP 5050 Shimadzu instrument. The source of radiation was a 60Co Theratron-Phoenix teletherapy unit (Atomic Energy Ltd., Ottawa, Canada).

Preparation of extracts: The collected leaves of $W$. tinctoria were dried in the shade and then subjected to size reduction. The resulting coarse consolidated powder was extracted using soxhlet apparatus for $48 \mathrm{~h}$, both with $70 \%$ ethanol at $70^{\circ} \mathrm{C}$ and methanol at $40^{\circ} \mathrm{C}$. The extracts were concentrated under vacuum, and lyophilized at $-55{ }^{\circ} \mathrm{C}$ to obtain the desired crude extracts. Such a version of the dried ethanolic extract of W. tinctoria (EWT) and the corresponding methanolic extract (MWT) were utilized for further investigation.

Antioxidant activity by DPPH method: A DPPH solution $(0.1 \mathrm{mM}$ in methanol) was prepared and $1 \mathrm{~mL}$ of this solution was added to $3 \mathrm{~mL}$ of sample solution in water at different concentrations. ${ }^{18,19}$ The resulting mixture was vortexes and then kept in the dark for equilibration at $25^{\circ} \mathrm{C}$. After a $30 \mathrm{~min}$ incubation time, the absorbance was taken at $517 \mathrm{~nm}$ using UV-Vis spectrophotometer and the half maximal inhibitory concentration $\left(\mathrm{IC}_{50}\right.$ ) values calculated. Ascorbic acid was used as a standard. The assays were carried out in triplicate and results expressed as mean \pm standard deviation.

Antioxidant activity by hydrogen peroxide method: A solution $(0.6 \mathrm{~mL})$ of hydrogen peroxide in phosphate buffer was mixed with different concentrations of EWT. These mixtures were allowed to stand for $10 \mathrm{~min}$ at room temperature and their absorbance measured at $230 \mathrm{~nm}$ against phosphate buffer used as the blank. ${ }^{20}$ The $\mathrm{IC}_{50}$ values were calculated after ensuring that the assay was carried out in triplicate at each concentration. The percentage inhibition (expressed as mean \pm standard deviation) was compared with ascorbic acid that was once again employed as the standard.

Exposure to gamma radiation: Whole-body gamma $(\gamma)$ irradiation was achieved using a ${ }^{60} \mathrm{Co}$ Theratron-Phoenix teletheraphy unit, Atomic Energy Ltd., Ottawa, Canada at a dose rate of $1.88 \mathrm{~Gy} / \mathrm{min}$.

Micronucleus assay: Chromosomal damage was evaluated by means of the micronucleus assay performed herein with rat peripheral blood reticulocytes by using a cridine orange $(\mathrm{AO})$ as a coating material. ${ }^{21}$ The experiment was carried out in six groups of rodents (six rats in each group) for 12 days. The treatment regimen and the subsequent experimental protocol is as detailed below:

Group 1: 0 Gy $\gamma$ radiation $+0.2 \mathrm{ml}$ distilled water (control)

Group 2: 2 Gy $\gamma$ radiation $+0.2 \mathrm{ml}$ distilled water (control)

Group 3: 0 Gy $\gamma$ radiation + EWT $(100 \mathrm{mg} / \mathrm{kg})$

Group 4: 2 Gy $\gamma$ radiation + EWT $(100 \mathrm{mg} / \mathrm{kg})$

Group 5: 0 Gy $\gamma$ radiation + EWT $(200 \mathrm{mg} / \mathrm{kg})$

Group 6: 2 Gy $\gamma$ radiation + EWT $(200 \mathrm{mg} / \mathrm{kg})$

From every single rat in each treatment group, $5 \mu \mathrm{L}$ of peripheral blood (without any added anticoagulant) was collected by tail vein puncture at $\mathrm{t}=24$ and $48 \mathrm{~h}$ post irradiation onto $\mathrm{AO}$-coated slides. These slides were covered immediately by using cover glass following which they were kept overnight in a refrigerator to allow the cells to settle as well as to maximize staining. A blue excitation at $488 \mathrm{~nm}$ and a yellow-to-orange barrier filter at $515 \mathrm{~nm}$ facilitated the visualization of the slides that were observed for 2000 reticulocytes of peripheral blood (identified by their reticulum structure with red fluorescence). The percentage of micronucleated reticulocytes (round in shape with a strong yellow-green fluorescence) was scored. The results have been expressed as mean \pm standard deviation $(\sigma)$ of the studied groups and ANOVA with TukeyKramer multiple comparisons tests applied for the ensuing statistical analysis.

Spleen colony assay: The protocol used for this assay mirrors the established method ${ }^{22}$ and accordingly, SD rats were divided into three groups with each group comprising of six animals. The treatment (12 days) given to each group was as follows:

Group 1: 6 Gy $\gamma$ radiation (control)

Group 2: 6 Gy $\gamma$ radiation + EWT $(100 \mathrm{mg} / \mathrm{kg})$

Group 3: 6 Gy $\gamma$ radiation + EWT $(200 \mathrm{mg} / \mathrm{kg})$

The desired ethanolic extract was administered to the animals in various groups (identified above) in appropriate amounts (100 mg/kg, $200 \mathrm{mg} / \mathrm{kg}$ ) immediately after exposure to the specified dose $(6 \mathrm{~Gy})$ of radiation. On the twelfth day (marking the end of the treatment period) post irradiation, all the rodents utilized for this assay were sacrificed by cervical dislocation. The spleen of these animals was cut out, fixed in Bouin's solution (composed of $1.2 \%$ saturated picric acid, 30 to $40 \%$ formalin, and glacial acetic acid in the ratio 15:5:1) and subsequently analyzed for the formation of colonies. The results are presented as mean \pm standard 
deviation $(\sigma)$ of the studied groups. Statistical analyses of the results were performed using ANOVA with Tukey-Kramer multiple comparisons test.

Comet Assay: A robust protocol ${ }^{23}$ with minor modifications ${ }^{24}$ was employed in carrying out this assay. Low melting point agarose dissolved in $1 \%$ phosphate buffered saline (PBS) was used to perform single-cell gel electrophoresis. This agarose solution was used to coat microscopic slides which were then kept at $4^{\circ} \mathrm{C}$ to facilitate the solidification of agarose. Further, $200 \mu \mathrm{L}$ of $0.8 \%$ agarose containing $50 \mu \mathrm{L}$ of treated cells (peripheral blood leukocytes of SD rats exposed to 4 Gy gamma radiation) were added to the slides following which they were dipped in pre-chilled Lysing solution (2.5 M NaCl, $100 \mathrm{mM}$ EDTA, $10 \mathrm{mM}$ Tris buffer within a $\mathrm{pH}$ range of 9 to $10,1 \% \mathrm{DMSO}, 1 \%$ Triton $\mathrm{X}$ ) and maintained at $4^{\circ} \mathrm{C}$ to enable cell lysis. Subsequently, the slides were thoroughly drained and placed in electrophoretic apparatus containing an alkaline $(\mathrm{pH} 10-12)$ electrophoresis buffer solution (300 mM NaOH, $1 \mathrm{mM}$ EDTA, $0.2 \%$ DMSO). After allowing for a 20 min equilibration period, electrophoresis was carried out for $30 \mathrm{~min}$ at $20 \mathrm{~V}$; the slides were sequentially washed with neutral Tris buffer, distilled water and kept for drying at $37^{\circ} \mathrm{C}$ for $2 \mathrm{~h}$. The comets were visualized on these dried, stained slides using Olympus BX-41 microscope and the more than 50 images captured were analyzed using the software CASP which measures DNA damage in terms of four standard descriptors including percentage DNA in tail, tail length, tail moment (TM) and olive tail moment (OTM). It would be instructive to point out here that the product of tail length and percentage of DNA in tail gives TM whereas OTM represents the product of the distance between the centers of gravity of the head and tail of the comet with percentage of DNA in the tail. The results were noted as mean \pm standard deviation $(\sigma)$ of the studied groups. ANOVA with Tukey-Kramer multiple comparisons test was used for statistically analyzing the data.

Isolation and characterization of phytoconstituents: A glass column $(500 \times 10 \mathrm{~mm})$ was cleaned, rinsed with acetone and dried completely. Silica gel slurry was prepared using chloroform and the slurry was carefully loaded into the column. A further $10 \mathrm{ml}$ chloroform was added to the column and it was kept overnight for proper setting and efficient packing of the stationary phase.

About $5 \mathrm{~g}$ of the dried ethanolic extract of $W$. tinctoria leaves was taken in a porcelain dish, mixed with $2 \mathrm{~g}$ silica gel in small increments to form soft dough and allowed to air dry overnight. This dried and activated sample was loaded on top of the silica bed that comprised the stationary phase. Care was taken to keep the mobile phase solvent well above the silica gel bed and the band of sample. Gradient elution (from 8:2 to 6:4 to $4: 6$ to $2: 8$ to $0: 10$ ) was carried out by using the specified mobile phase compositions of ethyl acetate and methanol. A flow rate of $2 \mathrm{~mL} / \mathrm{min}$ was maintained throughout the chromatographic separation process and approximately 200 fractions of $5 \mathrm{~mL}$ portion each were collected.

Those fractions having the same $R_{\mathrm{f}}$ values in TLC as observed under UV light and iodine chamber were pooled and concentrated under reduced pressure. The two prominent bands that were obtained as a result of this procedure presented optimal $R_{\mathrm{f}}$ values in mobile phases composed of ethyl acetate:methanol $=7: 3$ and hexane:ethyl acetate:methanol:water $=8: 4: 1: 0.5$. The compounds corresponding to these two bands were obtained in purified form by passing through another column prepacked with sephadex LH-20 using pure methanol as eluent. After all the eluent was evaporated in vacuo, the dried compound samples were packed in air tight containers and stored at temperatures below $20^{\circ} \mathrm{C}$. These isolated compounds, labeled I and II were characterized and their physicochemical as well as spectroscopic data is as follows:

Compound I: Pale yellow crystalline powder; $R_{\mathrm{f}}=0.72$ (ethyl acetate:methanol $=7: 3) ; \mathrm{mp} \mathrm{330-332}{ }^{\circ} \mathrm{C}$; IR $(\mathrm{KBr}) \mathrm{cm}^{-1}: 3415(\mathrm{OH}$ stretching), 3125 (aromatic CH stretching), 2960 (alkane $\mathrm{CH}$ stretching),
$1661(\mathrm{C}=\mathrm{O}), 1440$ ( $\mathrm{C}=\mathrm{C}$ aromatic stretching), 1166 (C-O), 836 (aromatic); ${ }^{1} \mathrm{H}$ NMR (DMSO-d, $\left.400 \mathrm{MHz}\right) \delta 12.97(\mathrm{~s}, 1 \mathrm{H}), 10.80-10.71(\mathrm{~m}, 1 \mathrm{H})$, 9.93-9.50 (m, 2H), $7.42(\mathrm{~d}, J=6.6 \mathrm{~Hz}, 2 \mathrm{H}), 6.89(\mathrm{~d}, J=10.8 \mathrm{~Hz}, 1 \mathrm{H})$, $6.67(\mathrm{~s}, 1 \mathrm{H}), 6.44(\mathrm{~d}, J=2.4 \mathrm{~Hz}, 1 \mathrm{H}), 6.19(\mathrm{~d}, J=2.4 \mathrm{~Hz}, 1 \mathrm{H}) ;{ }^{13} \mathrm{C} \mathrm{NMR}$ (DMSO-d, $100 \mathrm{MHz}) \delta 182.0,164.5,161.9,157.7,150.1,146.2,122.0$, $119.4,116.5,113.8,104.1,103.3,99.3$, 94.2; ESI MS $(\mathrm{m} / z$, relative abundance) $287\left[\mathrm{M}^{+}, 100\right]$

Compound II: Orange crystalline powder; $R_{\mathrm{f}}=0.74$ (hexane:ethyl acetate:methanol:water $=8: 4: 1: 0.5) ; \mathrm{mp} 254-258{ }^{\circ} \mathrm{C}$; IR $(\mathrm{KBr}) \mathrm{cm}^{-1}$ : 3452 (OH stretching), 3064 (aromatic $\mathrm{CH}$ stretching), 2976 (alkane $\mathrm{CH}$ stretching), $1734(\mathrm{C}=\mathrm{O}), 1458(\mathrm{C}=\mathrm{C}$ aromatic stretching), 752 (aromatic); ${ }^{1} \mathrm{H}$ NMR (CD $\left.\mathrm{OD}, 400 \mathrm{MHz}\right) \delta 7.79-7.72(\mathrm{~m}, 3 \mathrm{H}), 7.32-7.30(\mathrm{~m}, 1 \mathrm{H})$, $3.30(\mathrm{~s}, 3 \mathrm{H}) ;{ }^{13} \mathrm{C}$ NMR $\left(\mathrm{CD}_{3} \mathrm{OD}, 100 \mathrm{MHz}\right) \delta 182.6,181.3,164.2,163.7$, $161.4,148.0,146.0,134.6,132.4,122.9,120.2,114.7,106.6,24.0$; ESI MS $\left(\mathrm{m} / \mathrm{z}\right.$, relative abundance) $271\left[\mathrm{M}^{+}, 100\right]$.

In vitro radioprotection by isolated compounds: In accordance to a reported method ${ }^{24}$ plasmid pBR322 DNA (100 ng) in neutral phosphate buffer $(0.1 \mathrm{M})$ was exposed to various concentrations of gamma rays (0 to $20 \mathrm{~Gy}$ ) with or without the isolated compounds. This piece of DNA was then subjected to electrophoresis on $0.8 \%$ agarose gel at $55 \mathrm{~V}$ for $2 \mathrm{~h}$. The damaged DNA was examined and the result interpreted in terms of free radical scavenging action. In a typical experiment of this nature, DNA damage such as strand breaks can be easily analyzed by evaluating the degree of formation of the open circular (oc) form (also called the linear form) of the plasmid DNA from its usual resting supercoiled (scc) state. The very same strategy in fact has been used to estimate the extent of damage in this scenario due to the indicated dose of ionizing radiation.

\section{RESULTS AND DISCUSSION}

Antioxidant activity of $W$. tinctoria leaf extract: Antioxidants are molecules that are able to interact with free radicals so as to terminate the chain reaction(s) propagated by these reactive intermediates and thus provide protection from cell damage. By their ability to donate hydrogen atoms or electrons, antioxidants scavenge free radicals thereby reducing the access of oxidants and other deleterious molecules to the cellular milieu. The in vitro antioxidant activity of EWT was assessed by the DPPH radical scavenging and hydrogen peroxide scavenging methods.

In the former assay, as the DPPH solution is mixed with that of a sample containing a substance capable of donating a hydrogen atom, the DPPH moiety that actually exists as a radical is converted to a reduced form. More specifically, the odd electron associated with one of the hydrazine nitrogen atoms in DPPH becomes paired off. This causes the solution to lose color stoichiometrically, a phenomenon which can be readily quantified. The $\mathrm{IC}_{50}$ of EWT in the DPPH radical scavenging assay was observed to be $290 \mu \mathrm{g} / \mathrm{mL}$ (Table 1).

Hydrogen peroxide is amongst the most stable of the ROS and considered to be one of the key species implicated in cellular injury through DNA damage. In peroxidation leading to oxidative degradation, an appropriate substrate promptly takes up one of the oxygen atoms of hydrogen peroxide and ends up getting completely oxidized. In the second method to evaluate antioxidant potential, the ability of EWT to scavenge hydrogen peroxide was determined spectrophoto metrically. The percentage scavenging was deduced and $\mathrm{IC}_{50}$ value was noted to be $410 \mu \mathrm{g} / \mathrm{mL}$ (Table 1). The antioxidant properties of EWT can prove to be beneficial by preventing the deleterious effects of radiation-induced ionization and nurturing cell growth through scavenging the free radicals produced in our system.

Radioprotective effect of $W$. tinctoria leaf extracts: Radiation-induced cell death is chiefly due to DNA damage, a phenomenon that commonly manifests as strand breaks. Since they can directly lead to chromosomal 
Table 1: Antioxidant Activity of EEWT

\begin{tabular}{cccccc}
\hline DPPH radical scavenging method & \multicolumn{3}{c}{ Hydrogen peroxide scavenging method } \\
\hline $\begin{array}{c}\text { Concentration } \\
(\mu \mathrm{g} / \mathrm{mL}) \text { of EWT }\end{array}$ & $\begin{array}{c}\text { Percentage } \\
\text { inhibition }\end{array}$ & $\begin{array}{c}\text { Percentage inhibition of } \\
\text { ascorbic acid (standard) }\end{array}$ & $\begin{array}{c}\text { Concentration } \\
(\mu \mathrm{g} / \mathrm{mL}) \text { of EWT }\end{array}$ & $\begin{array}{c}\text { Percentage } \\
\text { inhibition }\end{array}$ & $\begin{array}{c}\text { Percentage inhibition of } \\
\text { ascorbic acid }(\text { standard })\end{array}$ \\
\hline 100 & $26.63 \pm 0.96$ & $64.64 \pm 0.05$ & 100 & $26.31 \pm 1.28$ & $44.06 \pm 0.02$ \\
200 & $41.83 \pm 0.78$ & $68.12 \pm 0.95$ & 200 & $32.87 \pm 1.77$ & $56.00 \pm 0.02$ \\
300 & $52.42 \pm 0.59$ & $74.22 \pm 0.80$ & 300 & $43.03 \pm 0.70$ & $60.47 \pm 0.02$ \\
400 & $61.26 \pm 0.48$ & $77.52 \pm 0.44$ & 400 & $47.85 \pm 0.70$ & $71.48 \pm 0.06$ \\
500 & $73.68 \pm 1.09$ & $85.30 \pm 0.11$ & 500 & $57.53 \pm 1.89$ & $80.72 \pm 0.08$ \\
& $\mathrm{IC}_{50}: 289.86 \mu \mathrm{g} / \mathrm{mL}$ & & & $\mathrm{IC}_{50}: 409.66 \mu \mathrm{g} / \mathrm{mL}$ & \\
\hline
\end{tabular}

aberrations and the loss of genetic material, such strand breaks are considered precursors to cell death. ${ }^{25}$ Misjoined or unrepaired DNA double strand breaks can produce deletions, translocations, and acentric or dicentric chromosomes. Furthermore, chromosomal damage is also evident in the form of fragments which, in turn, appear in the form of micronuclei in rapidly proliferating cells. ${ }^{26}$ Therfore, the animals in various treatment groups within this study, when subjected to whole-body gamma irradiation are bound to show an increase in micronucleated reticulocytes.

Our data from the micronucleus assay is presented in two panels (Figure 1) that correspond to each of the two time points under investigation. In the control group wherein the animals were exposed to 2 Gy gamma radiations, a time-dependent induction of micronuclei was observed. The number of micronucleated reticulocytes in the control SD rats increased from $3.4 \pm 0.18$ per 100 cells at $t=24 \mathrm{~h}$ to $8.9 \pm 0.06$ at $\mathrm{t}=48 \mathrm{~h}$. The mean percentage levels of micronucleated reticulocytes in the extract-treated animal groups were $2.45 \pm 0.21$ (in group 4 administered $100 \mathrm{mg} / \mathrm{kg} \mathrm{EWT}$ ) and $2.87 \pm 0.24$ (in group 6 administered 200 $\mathrm{mg} / \mathrm{kg}$ EWT) at the $24 \mathrm{~h}$ time point while the corresponding numbers for the same treatment groups stood at $5.46 \pm 0.32$ and $6.41 \pm 0.09$ respectively at the $48 \mathrm{~h}$ time point. It was gratifying to note such a substantial decrease in micronucleus induction subsequent to the administration of $100 \mathrm{mg} / \mathrm{kg}$ and $200 \mathrm{mg} / \mathrm{kg}$ of EWT to the appropriate treatment groups immediately after radiation exposure. Such a post irradiation decrease in the frequency of micronucleated reticulocytes is clearly suggestive of an efficient DNA repair mechanism.

In Spleen colony assay, that is considered one of the gold standards to evaluate the radioprotective ability of an agent, colonies that form in the spleen from the surviving stem cells following radiation exposure are counted. This count provides a rather accurate assessment of bone marrow cell survival subsequent to irradiation. Whole-body gamma irradiation in SD rats to the tune of 6 Gy resulted in low spleen colony count $(12 \pm 1.52)$. It can be readily seen from Figure 2 that administration of EWT in different doses $(100 \mathrm{mg} / \mathrm{kg}$ and $200 \mathrm{mg} / \mathrm{kg})$ to these irradiated animals resulted in a dose-dependent enhancement in the number of spleen colonies $(26.4 \pm 2.64$ and $38 \pm 2.66$ respectively). Since each nodule or spleen colony arises from a single marrow stem cell, this experimental data indicates the ability of the extract to aid the recovery of the hematopoietic system following irradiation, with a higher dose of the extract being more productive in this regard. It can be readily deduced from the above experiments that the ethanolic extract of $W$. tinctoria leaves offer protection towards cellular DNA by preventing strand breaks and micronucleus formation as well as by restoring spleen colony counts to pre-radiation exposure threshold level.

The radioprotection afforded by the alcoholic extracts was reinforced after performing alkaline single-cell gel electrophoresis or the comet assay that is a rapid yet sensitive technique for the evaluation of DNA damage and repair in terms of double or single strand breaks. Radiation exposure results in fragmentation of cellular DNA and such fragmented DNA moves faster from the nucleus than the DNA from unirradiated cells under the influence of an electric field. Upon staining, those cells having strand breaks in their DNA complement appear as comets with the DNA fragments therein constituting the tail of the comet whereas normal cells retain a circular, disc-like appearance. Development of the comet is clearly displayed in the panels of the second row in Figure 3 while the top panel of this illustration represents an unirradiated cell. Close visual inspection of the panels in the two remaining rows of this Figure indicate a gradual shift to the normal appearance in the post irradiated, extract treated cells suggestive of the beneficial effect of the extracts.

The comet assay more specifically quantities DNA damage in the form of various parameters viz. percentage DNA in tail, tail length, TM and OTM as described earlier in the experimental section. As portrayed in Figure 4, there is a marked increase in each of the four parameters after radiation exposure. These parameters, however, decrease with time due to repair process that tends to rejoin the broken DNA strands. Normally, quantification of the repair efficiency of the cells is done on the basis of the comet parameters of cellular DNA through the repair index (CRI) that is defined as

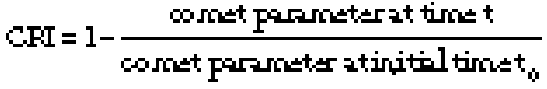

Reiterating the point made above, it can be seen from the panels located in the bottom two rows of Figure 3 that administration of the alcoholic extracts to the irradiated animals accelerated the recovery of the affected cells as they seem to regain their normal circular appearance, indicating an enhancement in DNA repair. Correspondingly, Figure 5 depicts the rapid increase in the blood leukocyte CRI in these animals as compared to the control SD rats.

Structural elucidation of ethanolic extract isolates: Following the isolation of two compounds corresponding to distinct bands that form during column chromatography of the dried extract, spectral data of these chemical entities were recorded in order to determine their identity. One of the isolates, compound I in its FT-IR spectrum showed stretching bands at $1661 \mathrm{~cm}^{-1}$ indicating the presence of carbonyl groups. A peak at a wave number $3415 \mathrm{~cm}^{-1}$ confirmed the existence of hydrogen bonded hydroxyl groups. Carbon-hydrogen stretching in aromatics was observed at $3125 \mathrm{~cm}^{-1}$. Other characteristic bands included the $\mathrm{C}=\mathrm{C}$ stretching at $1440 \mathrm{~cm}^{-1}$ and aromatic substitution at $836 \mathrm{~cm}^{-1}$. The compound's ${ }^{1} \mathrm{H}$ NMR spectrum did not possess any protons in the aliphatic region and seemed to contain only aromatic protons along with an aklenyl proton. Besides, four rather broad signals seen between 9.50 and 12.97 ppm, 


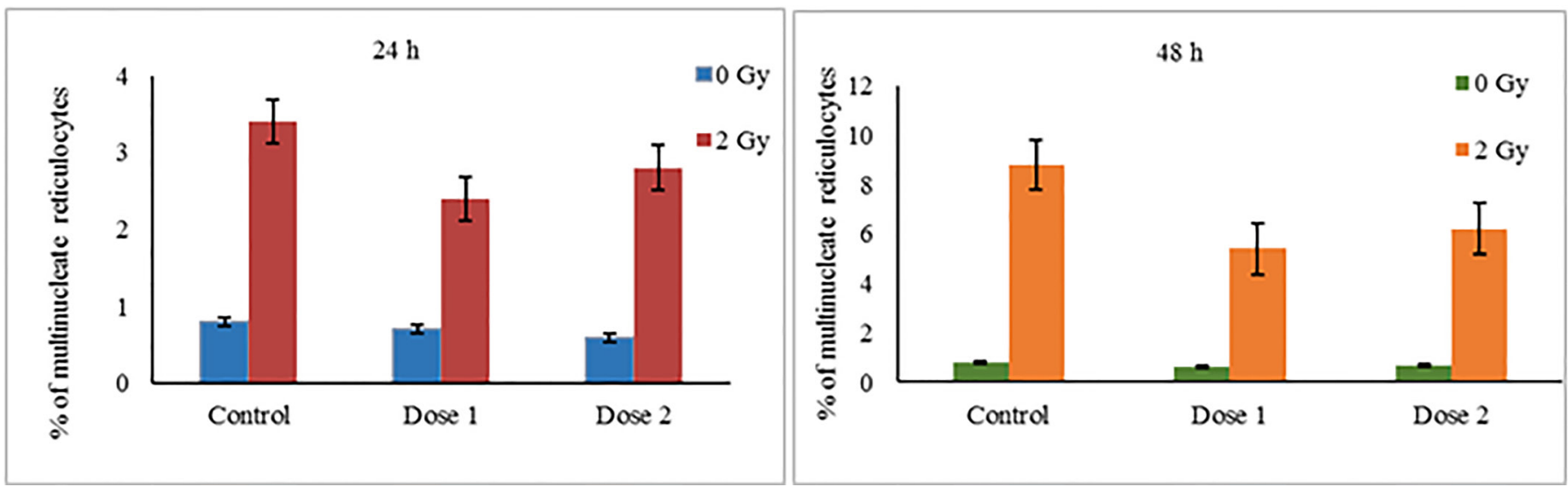

Figure 1: Effect of administration of ethanolic extract of Wrightia tinctoria leaves on micronucleus induction in SD rats $24 \mathrm{~h}$ and $48 \mathrm{~h}$ after exposure to $2 \mathrm{~Gy}$ whole-body gamma radiation. Values are expressed as mean $\pm \sigma(n=6)$. Data were analysed using ANOVA with Turkey-Kramer multiple comparisons test.

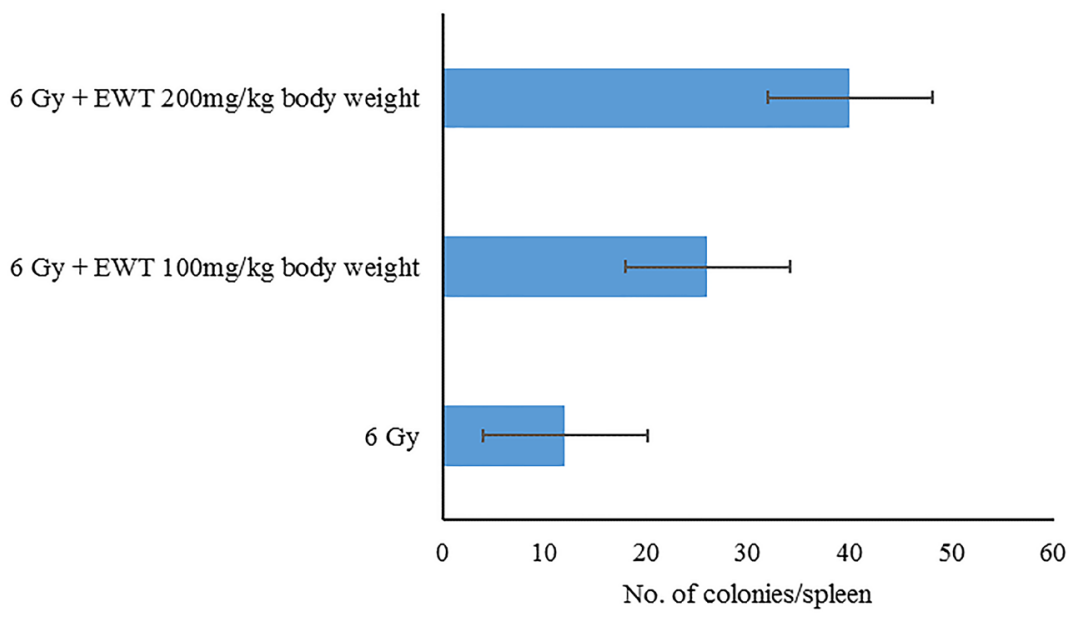

Figure 2: Effect of administration of ethanolic extract of Wrightia tinctoria leaves on spleen colony formation in rats exposed to 6 Gy whole-body gamma radiation for a 12-day period. Values are expressed as mean $\pm \sigma(n=2)$. Data were analyzed using ANOVA with TukeyKramer multiple comparisons test.
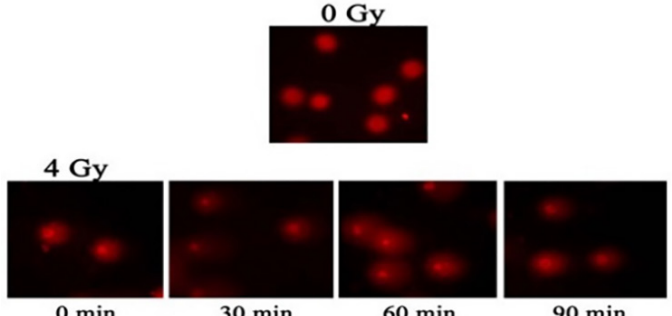

$4 \mathrm{~Gy}+\mathrm{EWT}$
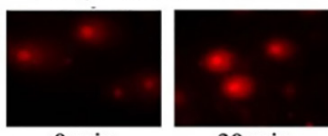

$30 \mathrm{~min}$

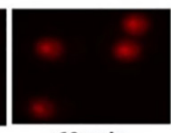

$60 \mathrm{~min}$

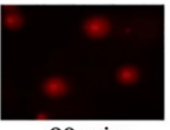

$4 \mathrm{~Gy}+\mathrm{MWT}$
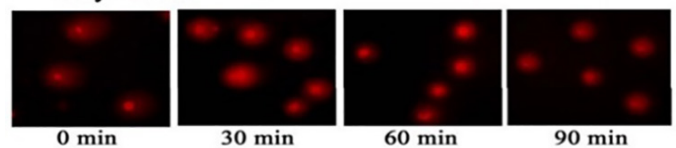

Figure 3: Comet Assay for DNA protection. three of them multiplets, suggested the possibility of the presence of four phenolic -OH groups. In ${ }^{13} \mathrm{C}$ NMR spectrum, a total of 14 signals pointed to the presence of at least that many carbon atoms. A single molecular ion peak at $\mathrm{m} / \mathrm{z}=287$ appeared in the compound's mass spectrum which matched with information for luteolin in the available library. Comparison of our data with literature reports ${ }^{27-29}$ showed the pure compound isolated to be the said tetrahydroxy flavone.

The FT-IR spectrum of compound II showed prominent stretching bands $1734 \mathrm{~cm}^{-1}$ suggesting that carbonyl groups may be present. A broad peak at a wave number of $3452 \mathrm{~cm}^{-1}$ confirmed the existence of one or more hydroxyl groups. Aromatic C-H stretching and alkane C-H stretching were observed at $3064 \mathrm{~cm}^{-1}$ and $2976 \mathrm{~cm}^{-1}$ respectively. The ${ }^{1} \mathrm{H}$ NMR spectrum of this compound was acquired in deuterated methanol and as such, contained only seven protons, four of which are aromatic and the others comprising a methyl group possibly attached to a phenyl moiety. It is likely that the other protons in the molecule, all of them in the form of hydroxyl groups based on the IR spectral input, have undergone a deuterium exchange. The presence of two carbonyl groups followed from the ${ }^{13} \mathrm{C}$ NMR spectrum that again displayed 14 signals. Careful assignment of the protons and carbons, aided with the comparison of data available in the literature ${ }^{30}$ suggested that the isolate could be a multiply substituted 


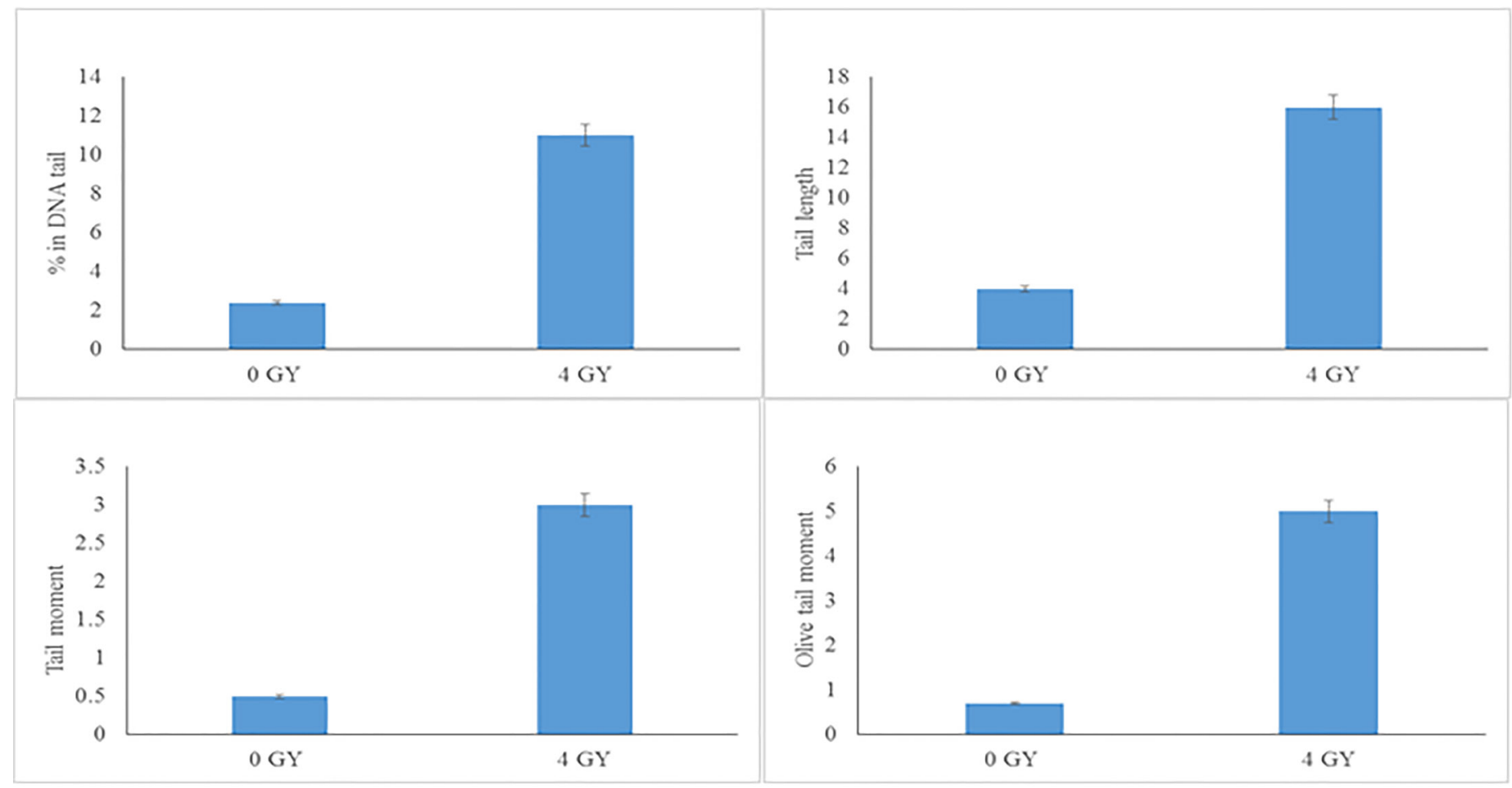

Figure 4: DNA damage expressed as various comet parameters: \% DNA tail, tail length, tail moment and olive tail moment in DNA of peripheral blood leukocytes exposed to whole-body 4 Gy gamma radiation. Comet assay has been performed immediately after radiation exposure.

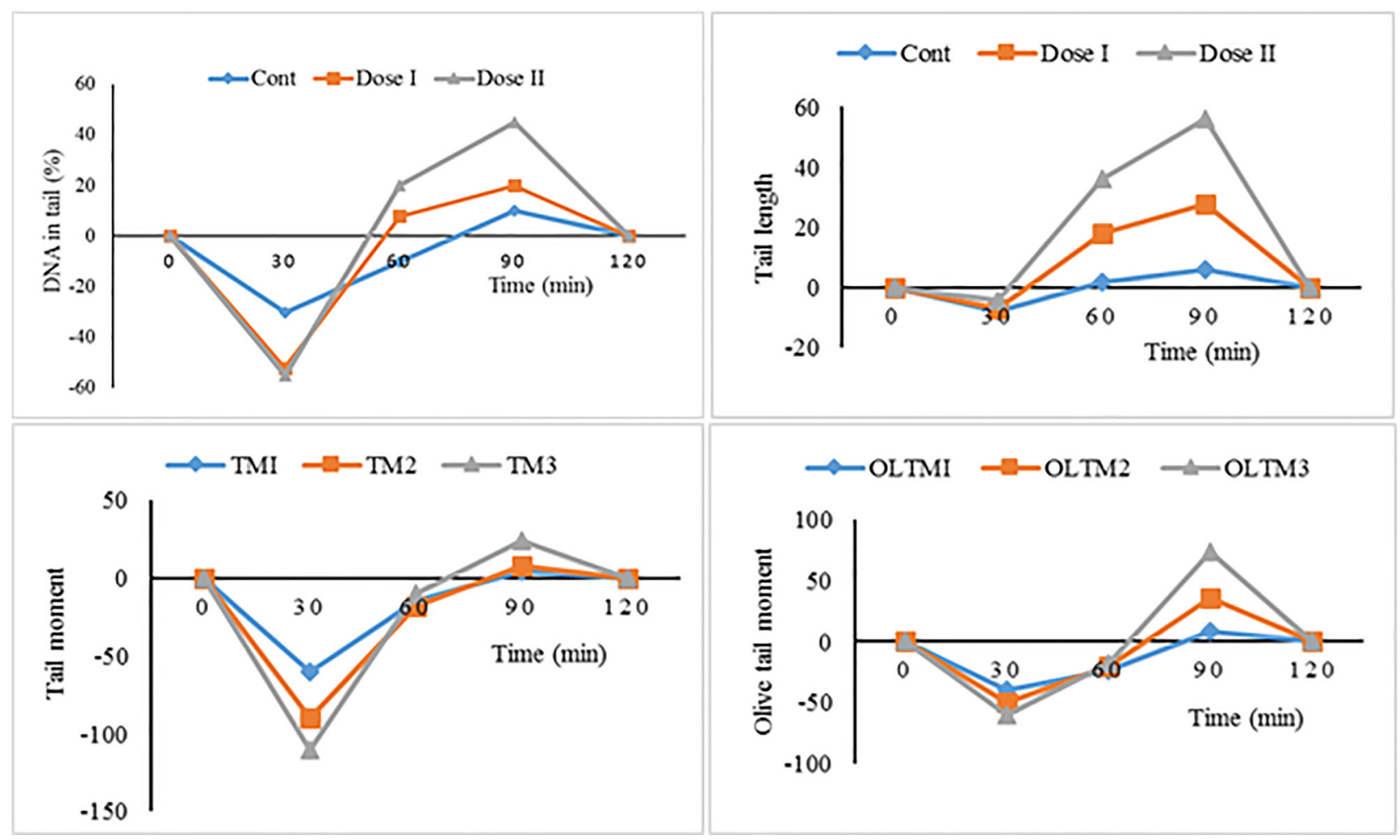

Figure 5: Effect of ethanolic extracts $n$ repair of peripheral blood leukocyte DNA of SD rats exposed to whole-body 4 Gy gamma radiation expressed as cellular repair index (CRI). 


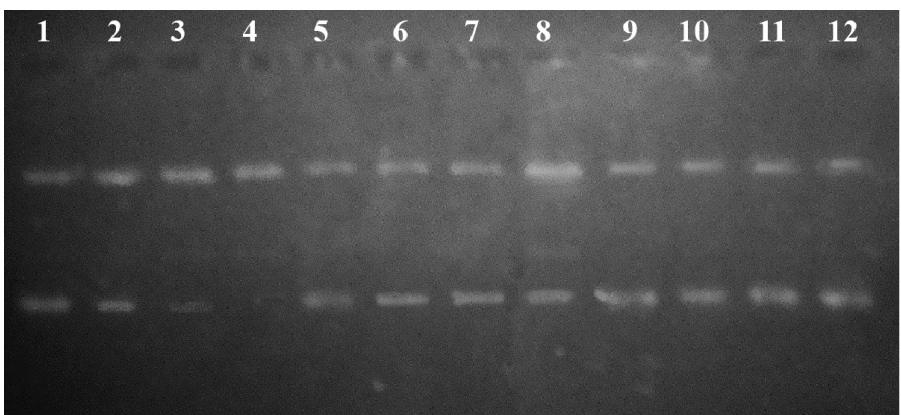

Figure 6: Digital image of fragmented plasmid pBR322 DNA exposed to gamma radiation with either the presence or absence of EWT isolates. The dose of radiation as well as the concentration of the isolates in each lane is as specified: Lane 1-0 Gy, Lane 2-5 Gy, Lane 3-10 Gy, Lane 4-20 Gy, Lane 5-0 Gy + $10 \mu \mathrm{g} / \mathrm{mL}$ compound I, Lane 6-5 Gy + $25 \mu \mathrm{g} / \mathrm{mL}$ compound I, Lane 7-10 Gy + $50 \mu \mathrm{g} / \mathrm{mL}$ compound I, Lane 8-20 Gy + $100 \mu \mathrm{g} / \mathrm{mL}$ compound I, Lane 9-0 Gy + $10 \mu \mathrm{g} / \mathrm{mL}$ compound II, Lane 10-5 Gy $+25 \mu \mathrm{g} / \mathrm{mL}$ compound II, Lane 11-10 Gy $+50 \mu \mathrm{g} / \mathrm{mL}$ compound II, Lane 12-20 Gy + $100 \mu \mathrm{g} / \mathrm{mL}$ compound II.

anthraquinone. The identity of the molecule was precisely confirmed as emodin when a single molecular ion peak at $\mathrm{m} / \mathrm{z}=271$ appeared in its mass spectrum that matched with data in the available library .

Plasmid DNA protection of isolates: Single and/or double strand breaks are the most common manifestations of the damage suffered by DNA upon exposure to ionizing radiation. Usually, events involving strand breaks correlate nicely with the rate as well as extent of the detection of oc (linear) form of plasmid DNA in simple in vitro experiments. ${ }^{24}$ In this work, strand break arising due to exposure of plasmid pBR322 DNA to ionizing radiation resulted in the scc form of the DNA being converted to oc i.e., the linear form. The consequent disappearance of supercoiled form of this plasmid DNA following exposure to ionizing radiation has therefore been taken as an index of DNA damage. The data presented in Figure 6 reveal that presence of either pure compound I or II partially prevented the plasmid DNA converting to the oc form following exposure to ionizing radiation. Irradiation normally induces the production of peroxides which go on to damage vital components of a cell like membranes as well as its key biomolecules, especially DNA, through the intermediacy of free radicals. The $\bullet \mathrm{OH}$ radicals from peroxides enhance the oxidative damage in cells and the degree of DNA damage effected by these radicals seems to be directly proportional to peroxidation. ${ }^{31}$ The results obtained herein thus indicated that the two main isolates of EWT, as noted above, protect DNA. These observations are quite promising and point to the radioprotective potential of the isolated compounds.

\section{CONCLUSION}

Protecting normal tissue during accidental radiation exposure as well as while administering radiation therapy is evolving as a major area of research. The viability of a cell translates into accurate transmission of its genetic information, a process which invariably depends on how well the structural integrity of its genomic DNA has been maintained. Since free radical mediated DNA damage is inevitable after radiation exposure, repair or better yet, prevention of DNA damage via free radical scavenging is considered to be a key mode that would afford radioprotection. Many natural products as well as synthetic chemical entities have been pursued over the years in a quest to identify potent radioprotectors. However, high toxicity at optimal protective doses seem to outweigh their beneficial effects.

Given the vast importance accorded to the leaves of $W$. tinctoria, we sought to take a close look at its ethanolic extract and examine the protection it affords against radiation-induced DNA damage. Two distinct compounds were isolated from this extract and unambiguously determined to be luteolin (compound I) and emodin (compound II). To the best of our knowledge, this represents the first report of these two chemical constituents in this plant in general, and its leaves, in particular. Well established assays performed on both the alcoholic leaf extract and the two isolates thereof clearly indicated their strong radioprotective potential against gamma radiation.

\section{ACKNOWLEDGEMENT}

The authors would like to thank Dr. Sabitha M, Principal, Amrita School of Pharmacy, Amrita Vishwa Vidyapeetham University, AIMS Kochi for constant support. In addition, they are grateful to KMCH College of Pharmacy (Coimbatore) and Radiant Research Pvt. Ltd. (Bangalore) for providing necessary laboratory facilities towards conducting the pharmacological evaluation.

\section{CONFLICT OF INTEREST}

The authors declare no conflict of interest.

\section{ABBREVIATIONS USED}

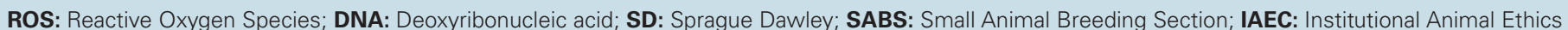

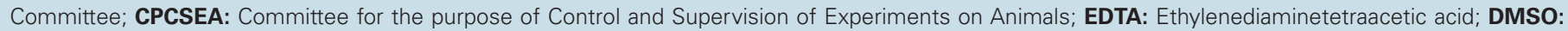

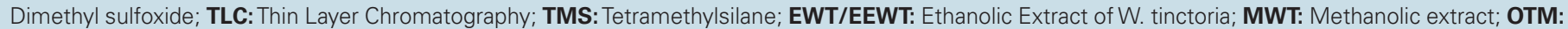
Tail moment (TM) and Olive tail moment.

\section{ABOUT AUTHORS}

Dr. Sathianarayanan: Working as an Assistant professor in Department of Pharmaceutical Chemistry at Amrita School of Pharmacy, Amrita University, Kochi. He completed his B. Pharm. and M. Pharm. from Dr. M G R Medical University, Chennai. He received his Ph. D. in Pharmacy from Karpagam University, Coimbatore. He is interests broadly include Semi-synthetic, Synthetic and Phytochemical Analysis. He has a strong academic background and extensive research experience with specialization in isolation and characterization of biologically active compounds.

After graduating with a B.Pharm (Hons.) degree from BITS Pilani, Dr. Ranganathan left for USA to pursue higher education. Over the next seven years, he obtained M.S. in Pharmaceutical Chemistry \& Ph.D. in Medicinal Chemistry from New Jersey and Minnesota respectively. He returned to India after a postdoctoral stint at the prestigious Johns Hopkins Medical School in Baltimore. Currently, he is pursuing his passion in pharmaceutical sciences by teaching as well as mentoring students in Organic, Medicinal \& Pharmaceutical Chemistry at Amrita School of Pharmacy, Kochi. 
Ms Asha Jose: Working as a research scholar in department of pharmacology at JSS University, Ooty. She Completed her UG from Amrita University, PG from Karpagam University and she is doing Ph.D from JSS Univesity. Her Doctral work mainly focused on the evaluation of cytotoxic activity against colon cancer from natural products. She published national and international journals. Her research area is Phytopharmacology.

Ms Diana Thomas Manapurathe: Is a doctoral student at the James Cook University, Townsville, Australia. She graduated in Bachelor of Pharmacy and Doctor of Pharmacy from Amrita School of Pharmacy, Kerala. Her doctoral research is focused in Blood pressure in patients with Peripheral artery disease.

\section{REFERENCES}

1. Nair CKK, Parida DK, Nomura T. Radioprotectors in radiotherapy. J Radiat Res. 2001;42(1):21-37.

2. Morgan WF, Day JP, Kaplan MI, McGhee EM, Limoli CL. Genomic instability induced by ionizing radiation. Radiat Res. 1996;146(3):247-58.

3. Ellis RE, Yuan JY, Horvitz HR. Mechanisms and functions of cell death. Ann Rev Cell Bio. 1991;7(1):663-98.

4. Halliwell B, Aruoma OI. DNA damage by oxygen-derived species. Its mechanism and measurement in mammalian systems. FEBS Lett.

5. Upadhyay SN, Singh S, Bhardwaj R, Chaudhury NK, Mathew TL. A preliminary study on 5-hydroxy-L-tryptophan, L-cysteine and cystamine. J Ind Chem Soc. 2003;80(1):33-5.

6. Devi PU, Ganasoundari A. Modulation of glutathione and antioxidant enzymes by Ocimum sanctum and its role in protection against radiation injury. Indian J Exp Biol. 1999;37(3):262-8.

7. Du J, Gebicki JM. Proteins are major initial cell targets of hydroxyl free radicals. Int J Biochem Cell Biol. 2004;36(11):2334-43.

8. Stadtman ER. Protein oxidation and aging. Free Radic Res. 2006;40(12):1250-8.

9. Ramchandra P, Basheermiya M, Krupadanam GLD, Srimannarayana G. Wrightial, a new terpene from Wrightia tinctoria. J Nat Prod. 1993;56(10):1811-2.

10. Reddy YRS, Venkatesh S, Ravichandran T, Murugan V, Suresh B. Antinociceptive activity of Wrightia tinctoria bark. Fitoterapia. 2000;73(5):421-3.

11. Mitra SK, Seshadri SJ, Venkataranganna MV, Gopumadhavan S. Reversal of parakeratosis, a feature of psoriasis by Wrightia tinctoria (in emulsion): Histological evaluation based on mouse tail test. Indian J Dermatol 1998;43:102-4.

12. Bigoniya P, Singh CS, Shukla A. Pharmacognostical and physicochemical standardization of ethnopharmacologically important seeds of Lepidium sativum Linn. and Wrightia tinctoria R. Br. Indian J Nat Prod Resour. 2011;2(4):464-71.

13. Bigoniya P. Immunomodulatory activity of Wrightia tinctoria bark alcoholic extract on rats. Current Pharma Res J. 2007;1:1-9.

14. Bigoniya P, Shukla A, Agrawal GP, Rana AC. Pharmacological screening of Wrightia tinctoria bark hydro-alcoholic extract. Asian J Exp Sci. 2008;22(3):235-44.

15. Sathianarayanan S, Selvam P, Jose A, George RM, Revikumar KG, Neyts J. Preliminary phytochemical screening and study of antiviral activity and cytotoxicity of Wrightia tinctoria. Int J Chem Sci. 2009;7(1):1-5.

16. George V, Koshy AS, Singh OV, Nayar MN, Pushpangadan P. Tryptanthrin from Wrightia tinctoria. Fitoterapia. 1996;67(6):553-4.

17. Sethuraman V, Sethuraman MG, Sulochana N, Nambi RA. Anti-inflammatory activity of Wrightia tinctoria flowers. Indian Drugs. 1984;22(3):158-9.
18. Nahak G, Sahu RK. In vitro antioxidative activity of Azadiracta indica and Melia azedarach leaves by DPPH scavenging assay. J Am Sci. 2010;6:123-8.

19. Parasuraman S, Kumar E P, Kumar A, Emerson S F. Free radical scavenging property and diuretic effect of triglize, a polyherbal formulation in experimental models. J Pharmacol Pharmacother. 2010;1(1):38-41.

20. Güder A, Korkmaz H. Evaluation of in vitro antioxidant properties of hydroalcoholic solution extracts Urtica dioica L., Malva neglecta Wallr and their mixture. Iranian J Pharm Res. 2012;11(3):913-23.

21. Hayashi M, Morita $T$, Kodama $Y$, Sofuni $T$, Ishidate $M$ Jr. The micronucleus assay with mouse peripheral blood reticulocytes using acridine orange-coated slides. Mutat Res Lett. 1990;245(4):245-9.

22. Menon A, Nagalekshmi R, Chandrasekharan DK, Nair CKK. Radiotherapeutic potential of the extracts of Andrographis paniculata and Swertia chirayita. J Pharmacol Toxicol. 2012;7:20-8.

23. Singh NP. Microgels for estimation of DNA strand breaks, DNA protein crosslinks and apoptosis. Mutat Res. 2000;455(1):111-27.

24. Chandrasekharan DK, Kagiya TV, Nair CKK. Radiation protection by 6-palmitoyl ascorbic acid-2-glucoside: Studies on DNA damage in vitro, ex vivo, in vivo and oxidative stress in vivo. J Radiat Res. 2009:50(3):203-12.

25. Livesey JC, Reed DJ. Chemical protection against ionizing radiation. Adv Radiat Biol. 1987;13:285-353.

26. Weiss JF, Simic MG. Introduction: Perspectives in radiation protection. Pharmacol Ther. 1998;39:1-2

27. Owen RW, Haubner R, MierW, Giacosa A, HullWE, Spiegelhalder B, et al. Isolation structure elucidation and antioxidant potential of the major phenolic and flavonoid compound in brined olive drupes. Food Chem Toxicol. 2003;41(5):703-17.

28. Ode OJ, Asuzu IU. Luteolin isolate from the methanol extract identified as the single-carbon compound responsible for broad antiulcer activities of Cassia singueana leaves. IOSR Journal of Pharmacy. 2014;4:17-23.

29. Fransisco V, Figueirinha A, Costa G, Liberal J, Lopes MC, Gracia-Rodriguez C, et al. Chemical characterization and anti-inflammatory activity of luteolin glycosides isolated from lemongrass. J Funct Foods. 2014;10:436-43.

30. Liu Z, Wei F, Chen LJ, Xiong HR, Liu YY, Luo F, Hou W, Xiao H, Yang ZQ. In vitro and in vivo studies of the inhibitory effects of emodin isolated from Polygonam cuspidatum on Coxsakievirus B4. Molecules 2013;18(10):11842-58.

31. Guha G, Rajkumar $\bigvee$, Mathew $L$, Kumar RA. The antioxidant and DNA protection potential of Indian tribal medicinal plants. Turk J Biol. 2011;35(2):233-42. 